\title{
Profile of Children Presenting with Epilepsy at a Tertiary Care Centre: A Hospital Based Cross Sectional Study
}

\author{
Amol Ramrao Suryavanshi ${ }^{\oplus 1}$, Sachin Bapurao Bodhgire ${ }^{\oplus 2}$, Shivaji Sangappa Phulari ${ }^{\odot 3}$, Rahul Digambarrao Anerao ${ }^{\oplus 4}$ \\ ${ }^{1}$ Associate Professor, Department of Paediatrics, Government Medical College and Hospital, Aurangabad, Maharashtra, India, ${ }^{2}$ Assistant Professor, Department of \\ Pediatrics and Neonatalogy, Government Medical College and Hospital, Aurangabad, Maharashtra, India, ${ }^{3}$ District Tuberculosis Officer, Health Department, Maharshtra, \\ India, ${ }^{4}$ Incharge, District Urban Leprosy, Health Department, Maharshtra, India.
}

\section{Abstract}

Background: Epilepsy is associated with significant mortality and morbidity. It is one of the common causes of childhood hospitalization. Regarding acute seizures episodes, there is limited data form the developing countries. This study aims to study the profile of children presenting with epilepsy at a Tertiary Care Centre. Subjects \& Methods: This was a hospital based, prospective cross-sectional study conducted at the 'epilepsy clinic' of Paediatric department of a Tertiary Care Center. Total 260 children with epilepsy and having the age of 1 months to 12 years attending to the epilepsy clinic during the study period, were studied for clinical features, types, imaging studies, EEG, etc. Results: Most of the children (59.61\%) affected with epilepsy were males. Majority of the cases (108) were in the age group 1 month to 1 year age. It was observed that, 185 cases $(71.15 \%)$ were born through pre term delivery. It was found that 214 cases $(82.31 \%)$ had abnormal EEG, 40 cases had abnormal CT scan and 46 cases had abnormal MRI. A significant number of children (60.38\%) had generalized tonic clonic seizures. Conclusion: Epilepsy in children is a common indication for hospital admission. Evaluation of the type of seizure type with specific EEG findings and other related investigations helps in early and appropriate initiation of treatment. It is utmost important that the children with seizures should be on regular long term follow up and treatment, for better prognosis and disease outcome.

Keywords: Epilepsy, Electroencephalogram (EEG), Computed tomography (CT), Magnetic resonance Imaging (MRI), generalized tonic clonic seizure

Corresponding Author: Sachin Bapurao Bodhgire, Assistant Professor, Department of Pediatrics and Neonatalogy, Government Medical College and Hospital, Aurangabad, Maharashtra, India.

E-mail: sbbodhgire15@gmail.com

Received: 1 August 2020

Revised: 10 September 2020

Accepted: 19 September 2020

Published: 10 October 2020

\section{Introduction}

Epilepsy is a chronic neurological disorder, which manifest as seizures and characterized by a recurrent tendency to have spontaneous, intermittent, abnormal electrical activity in a part of the brain. ${ }^{[1]}$ Across the world, epilepsy is a common medical illness seen in paediatric hospitals. Epilepsy is one of the major cause for hospital admissions in children. The condition is more commonly seen in developing countries with increased prevalence in younger children. ${ }^{[2,3]}$ The statistical data revealed that $0.5-1 \%$ of all children have epilepsy. ${ }^{[4]}$ It is estimated that, the incidence of epileptic disorder is highest in the age group ranging from one year to two years of age and that is associated with mental retardation and cerebral palsy. ${ }^{[5]}$

Epilepsy is seen among all age groups with different etiologies. But it is now known that childhood epilepsy has a better prognosis when compared to epilepsy in adults. ${ }^{[6]}$ Worldwide, the prevalence rate of epilepsy has a different pictures in different parts of the globe. It has a wide range and has been reported between 3/1000 and 22.2/1000. ${ }^{[7,8]}$ The developing countries shows more prevalence rate as compared to western and developed countries. The WHO estimates that the epilepsy patients from developing countries contribute about $80 \%$ of the world's all epileptic cases. ${ }^{[9]}$ Studies suggest that, before 16 years of age around $4-10 \%$ of children have an experience of seizure, where $1 / 5$ th of total children with unprovoked seizures may develop epilepsy. ${ }^{[10]}$

However, seizure may be the initial presentation of serious medical condition like meningitis/ cerebral malaria. So the early investigations with proper clinical correlation with early start of the appropriate treatment is the key of better outcome. Epilepsy being common in childhood, chronic in nature and associated with psychological implications, it contributes about $1 \%$ of the global burden of disease. ${ }^{[11]}$ 
So in view of this background, this study was formulated with the objective of to study the clinical profile of epilepsy in children attending the Government Tertiary Care Center in Maharashtra.

\section{Subjects and Methods}

The study was a hospital based, prospective cross-sectional study, conducted at the 'epilepsy clinic' of Paediatric department of Government Medical College and Hospital Aurangabad. Total 260 children with epilepsy and having the age of 1 months to 12 years attending to the epilepsy clinic during the period of April 2018 to January 2020 were included in this study.

Clinical history was taken including patients age and gender, associated symptoms (fever, cough, rhinorrhea, vomiting, diarrhea and headache), family history of seizure or epilepsy and consanguinity, birth history, developmental history, immunization status as well as details of the seizure history, type of seizure, duration, frequency, semiology and treatment history were recorded.

Detail general examination, anthropometry, neurological examination and examination of co-morbid conditions conducted meticulously. Routine laboratory investigations were done including complete blood picture, CSF study, (if indicated), complete urine examination, serum C-reactive protein, serum electrolytes, blood glucose estimation as per protocol for seizure. Appropriate investigation in the form of EEG, CT scan or MRI was done according to etiology and findings were tabulated.

All participants were following up regularly for clinical examination at 4 weekly intervals and blood parameters at 3 monthly intervals. They were asked to follow up in between if any new neurological symptoms, seizures and other new symptoms develop in participants. After briefing the details about the study to all the participants, a written consent was taken from all of them. The ethical committee of the Government Medical Aurangabad approval was obtained prior to the commencement of the study. Data was recorded in predesigned proforma and expressed in terms of percentage.

\section{Results}

Total number of cases attending the epilespy clinic during the study period were 260 . Out of these, 155 (59.61\%) cases were male, and $105(40.39 \%)$ were female. The male to female ratio was 0.67 [Table 1].

In the present study, the cases were ranged from 1 month to 12 years. Majority of the cases (108) were from the age group 1 month to 1 year age, consisting of 71 male and 37 females. Followed by 70 cases belonging from the age group 1 to 4 years age group and 47 cases from 4 to 8 years age group [Table 2].

\begin{tabular}{|c|c|c|}
\hline Gender & $\begin{array}{l}\text { Number children } \\
(n-260)\end{array}$ & Percentage \\
\hline Male & 155 & $59.61 \%$ \\
\hline Female & 105 & $40.39 \%$ \\
\hline
\end{tabular}

\begin{tabular}{|c|c|c|}
\hline Age & Male $(n=155)$ & Female $(n=105)$ \\
\hline $\begin{array}{l}1 \text { Month to } 1 \\
\text { years }(n=108)\end{array}$ & $71(45.82 \%)$ & $37(35.23 \%)$ \\
\hline $\begin{array}{l}\text { 1to } 4 \text { years } \\
(\mathrm{n}=70)\end{array}$ & $41(24.45 \%)$ & $29(27.61 \%)$ \\
\hline $\begin{array}{l}4 \text { to } 8 \text { years } \\
(\mathrm{n}=47)\end{array}$ & $24(15.48 \%)$ & $23(21.90 \%)$ \\
\hline $\begin{array}{l}8 \text { to } 12 \text { years } \\
(\mathrm{n}=35)\end{array}$ & $19(12.25 \%)$ & $16(15.26 \%)$ \\
\hline
\end{tabular}

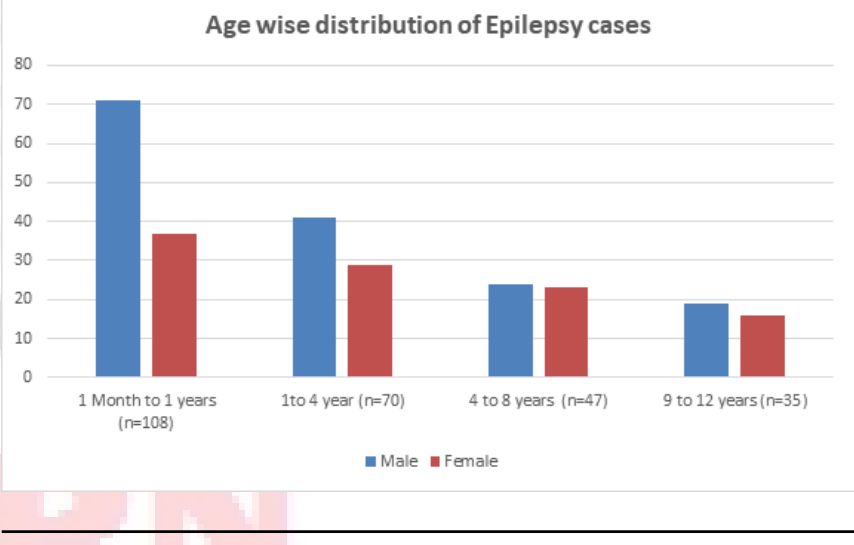

185 cases $(71.15 \%)$ were born through pre term delivery, 69 (26.55\%) were termed, and 06 cases $(2.30 \%)$ with post term delivery. Among the cases with pre term delivery, 107 were males and 78 were females [Table 3].

Table 3: Distribution of Epilepsy cases according to type of delivery

\begin{tabular}{llll}
\hline $\begin{array}{l}\text { Type of } \\
\text { delivery }\end{array}$ & $\begin{array}{l}\text { Male } \\
(\mathbf{n = 1 5 5 )}\end{array}$ & $\begin{array}{l}\text { Female } \\
(\mathbf{n = 1 0 5})\end{array}$ & $\begin{array}{l}\text { Total } \\
(\mathbf{n = 2 6 0})\end{array}$ \\
\hline Pre term & 107 & 78 & 185 \\
& & & $(71.15 \%)$ \\
\hline $\begin{array}{l}\text { Term deliv- } \\
\text { ery }\end{array}$ & 46 & 23 & 69 \\
Post term & 02 & 04 & $06(2.30 \%)$ \\
\hline
\end{tabular}

Electroencephalogram (EEG) was performed in all the cases. It was found that 214 cases $(82.31 \%)$ had abnormal EEG, while $46(17.69 \%)$ cases had normal EEG. Out of 142 cases in whom CT scan were done, $102(71.83 \%)$ had normal CT scan, 
while 40 cases $(28.17 \%)$ had abnormal CT scan. Magnetic resonance imaging (MRI) was done in 118 cases, out of which 72 cases $(61.02 \%)$ had normal MRI and 46 cases $(39.98 \%)$ had abnormal MRI [Table 4].

Out of total study population (260), 157 (60.38\%) cases were presented with GTCS, 74 (28.46\%) with CPS, 15 (5.76\%) with mixed seizures, 7 (2.69\%) with myoclonic seizures and $6(2.31 \%)$ with partial seizure [Table 5].

Distribution of cases according to types of Epilepsy

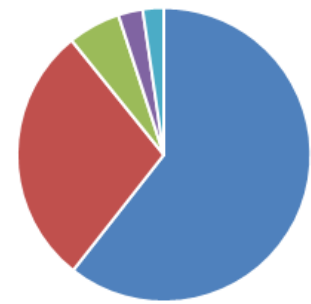

- Generalized tonic clonic seizure (GTCS) - Complex partial seizure (CPS) " Mixed Sezure - Myoclonic Sezure

- Simple Partial Seizure

\section{Discussion}

Epilepsy is one of the common disorder encountered in pediatric age group, requiring hospital admission. The prevalence rises in developing countries, like India. It also increases the morbidity and mortality. Thus, it becomes very essential to catch the disease early and treat accordingly to control the disease activity. Thus, the present study was planned to assess the clinical profile of epilepsy in pediatric age group.

Infants in their first year of life accounted for the highest incidence of epilepsy overall. In this study also, we found the male predominance $($ male/female $=1.6: 1)$ with higher prevalence of seizures in the age group of 1 month to 1 year. Shetty et al., and Najeeb et al. noticed more number of males getting seizures and the findings are in correlation with those of present study. ${ }^{[12,13]}$ S. Saravanan conducted a study in South India to find out the profile of seizure cases admitted in the hospital, was observed that seizures were being predominant in male children. ${ }^{[14]}$ Similar trend of male preponderance was also noted in studies conducted by Badwaik et al, ${ }^{[15]}$ Thasni et al, ${ }^{[16]}$ Pal et al. ${ }^{[17]}$

This gender difference in prevalence rates might be attributed to some extent, to the female sex hormones i.e. estrogen and progesterone, which are known to affect the seizure threshold in females. ${ }^{[18]}$ Also, in developing country like India, social stigma, need for male accompaniment for visiting hospital, lack of awareness and education might contribute to lower prevalence of epilepsy in female population. ${ }^{[19]}$ Again, it was because of increased care given to male sex while female babies were denied of medical care when it was needed.

In this study we observed that, 185 cases $(71.15 \%)$ were born through pre term delivery. This is similar to Ajay et al, ${ }^{[20]}$ who reported as more incidence of seizures in pre-term babies (61.4\%). Rennie JM et al, ${ }^{[21]}$ Bernes and Kaplan also reported that the incidence of seizures were commonly associated with the children delivered pre term. ${ }^{[22]}$

In the present study the generalized tonic-clonic seizures were the most common seizure type among the study cases. Shakya et al. conducted a study in Nepal to study the relative frequencies of various epileptic seizures. He also access the age at onset of different types of seizure in childrens from Nepal and found that, the most common seizure type was generalized tonic-clonic seizure (36\%), which was followed by tonic type $(16 \%)$, complex partial type $(14 \%)$, atonic type $(12 \%)$, and absence $(10 \%){ }^{[23]}$

Najeeb et al reported similar observations. In infants and children GTCS were commonest $(58.2 \%)$; next in the order noticed were simple partial $(20 \%)$, and others like complex partial (9.1\%), myoclonic (5.6\%) and absence seizures (7.3\%) were observed. ${ }^{[13]}$ Study done by Ojha et al, ${ }^{[24]}$ also observed that, the generalized tonic-clonic as the most common (69.9\%) type of seizures, which was followed by partial seizures $(19.8 \%)$. Similar trends were reported by Badwaik et al, ${ }^{[15]} \mathrm{Pal}$ et al, ${ }^{[17]}$ Sil et al, ${ }^{[25]}$ in their epidemiological studies, wherein GTCS were the predominant type of epilepsy reported in these age groups.

\section{Limitations of the Study:}

There are few limitations to our study. The main limitation to this study was that, it was a single hospital based study. Hence, metacentric and community based studies are needed to generalize the results in general population. The other limitation was that the parents may not have been able to give us an accurate past history and birth history.

\section{What study adds to existing knowledge?}

The present study helps to identify the current trend in epilepsy in the region. It also helps to identify the commonly affected age group, thus it will help to formulate preventive strategies which ill majorly target the commonly affected age group.

\section{Conclusion}

Epilepsy in children is one of the most common cause of hospital admission. Evaluation of the seizure type with specific EEG findings helps in early and appropriate initiation of treatment. It can be made from our study that most common 
Table 4: Distribution of Epilepsy cases according to findings in Neuroimaging (EEG/CT/MRI Scan) Tests

\begin{tabular}{llll}
\hline Results & Electro Encephalogram $(\mathrm{n}=260)$ & $\begin{array}{l}\text { Computed Tomogra- } \\
\text { phy }(\mathrm{n}=142)\end{array}$ & $\begin{array}{l}\text { Magnetic Resonance Imag- } \\
\text { ing }(\mathrm{n}=118)\end{array}$ \\
Normal & $46(17.69 \%)$ & $102(71.83 \%)$ & $72(61.02 \%)$ \\
Abnormal & $214(82.31 \%)$ & $40(28.17 \%)$ & $46(38.98 \%)$ \\
\hline
\end{tabular}

Table 5: Distribution of cases according to types of Epilepsy

\begin{tabular}{|c|c|c|c|}
\hline Type of seizure & Male $(n=155)$ & Female $(n=105)$ & Percentage $(n=260)$ \\
\hline $\begin{array}{l}\text { Generalized tonic clonic seizure } \\
\text { (GTCS) }\end{array}$ & 89 & 68 & $157(60.38 \%)$ \\
\hline Complex partial seizure (CPS) & 46 & 28 & $74(28.46 \%)$ \\
\hline Mixed Seizure & 09 & 06 & $15(5.76 \%)$ \\
\hline Myoclonic Seizure & 05 & 02 & $07(2.69 \%)$ \\
\hline Simple Partial Seizure & 05 & 01 & $06(2.31 \%)$ \\
\hline
\end{tabular}

type of seizure is GTCS. In such epileptic cases regular investigations and follow up with pediatrician is important for better outcome.

\section{References}

1. Guidelines for epidemiologic studies on epilepsy. Commission on Epidemiology and Prognosis, International League Against Epilepsy. Epilepsia. 1993;34(4):592-596. Available from: https://doi.org/10.1111/j.1528-1157.1993.tb00433.x.

2. Vining EP. Pediatric seizures. Emerg Med Clin. 1994;12(4):973-988.

3. Singhi P, Singhi S. Neurocysticercosis in children. Indian J Pediatr. 2009;76(5):537-545. Available from: https://dx.doi. org/10.1007/s12098-009-0139-5.

4. Ottman R. Progress in the genetics of the partial epilepsies. Epilepsia. 2001;42(5):24-30.

5. Kramer U. Epilepsy in the first year of life: A review. J Child Neurol. 1999;14(8):485-489. Available from: https://doi.org/ $10.1177 / 088307389901400801$.

6. Stafstrom CE, Carmant L. Seizures and Epilepsy: An Overview for Neuroscientists. Cold Spring Harb Perspect Med. 2015;5(6):a022426-a022426. Available from: https://dx, doi. org/10.1101/cshperspect.a022426.

7. Beilmann A, Napa A, Sööt A, Talvik I, Talvik T. Prevalence of Childhood Epilepsy in Estonia. Epilepsia. 1999;40(7):10111019. Available from: https://dx.doi.org/10.1111/j.1528-1157. 1999.tb00811.x. doi:10.1111/j.1528-1157.1999.tb00811.x.

8. Serdaroglu A, Ozkan S, Aydin K, Gücüyener K, Tezcan S, Aycan S. Prevalence of Epilepsy in Turkish Children Between the Ages of 0 and 16 Years. J Child Neurol. 2004;19(4):271-274. Available from: https://doi.org/10.1177/ 088307380401900406 .

9. ;2005.

10. Mcabee GN, Wark JE. A practical approach to uncomplicated seizures in children. Am Fam Physician. 2000;62(5):11091116.
11. Leonardi M, Bedirhan Ustun T. The Global Burden of Epilepsy. Epilepsia. 2002;43:21-25. Available from: https: //dx.doi.org/10.1046/j.1528-1157.43.s.6.11.x.

12. K SS, S AT, V KG. Etiological study of seizures among paediatric age group (1-18 years) in tertiary care medical college hospital. Int J Pediatr Res. 2017;4(4):259-263. Available from: https://doi.org/10.17511/ijpr.2017.i04.03.

13. Najeeb S, Qureshi AM, ur Rehman A, Ahmad F, Shah S, Khan AY, et al. Aetiology and types of neonatal seizures presenting at Ayub Teaching Hospital Abbottabad. J Ayub Med Coll Abbottabad . 2012;24(1):33-37.

14. Saravanan S. Profile of children admitted with seizures in a tertiary care hospital in South India. J Dent Med Sci. 2013;11(4):56-61. Available from: https://doi.org/10.9790/ 0853-1145661.

15. Badwaik RT, , Mahajan HM, Borkar AS, Honrao R, Chopde SS. A Drug Utilization Study of Antiepileptic Drugs Use in a Tertiary Care Hospital of Central India. Journal of Contemporary Medicine and Dentistry. 2015;3(2):3338. Available from: https://dx.doi.org/10.18049/jcmad/327. doi:10.18049/jcmad/327.

16. Thasni K, Abdurahiman P, Shamna S. Assessment of prescription pattern and quality of life in patients with epilepsy: A tertiary care hospital based prospective study. Int J Med Health Res. 2017;3(10):106-111.

17. Pal A, Prusty S, Sahu PK, Trupti S. Drug utilization pattern of antiepileptic drugs: a pharmacoepidemiologic and pharmacovigilance study in a tertiary teaching hospital in India. Asian J Pharmaceut Clinic Res. 2011;4(1):96-99.

18. Mac TL, Tran DS, Quet F, Odermatt P, Preux PM, Tan CT. Epidemiology, aetiology, and clinical management of epilepsy in Asia: a systematic review. The Lancet Neurology. 2007;6(6):533-543. Available from: https://dx. doi.org/10.1016/s1474-4422(07)70127-8. doi:10.1016/s14744422(07)70127-8.

19. George J, Jose J, Kulkarni DA, Pol RR, Shalavadi MH, Mangannavar CV. Evaluation of Drug Utilization and Analysis of Anti- Epileptic Drugs at Tertiary Care Teaching Hospital. Int J Pharm Pract. 2016;9(3):189-194. Available from: https: 
//dx.doi.org/10.5530/ijopp.9.3.10.

20. Kumar A, Gupta V, Kachhawaha JS, Singla PN. Biochemical abnormalities in neonatal seizures. Indian Pediatr. 1995;32(4):424-428.

21. Rennie JM. Neonatal seizures. Eur J Pediatr. 1997;156(2):83-87. Available from: https://dx.doi.org/ $10.1007 / \mathrm{s} 004310050559$.

22. Bernes SM, Kaplan AM. Evolution of Neonatal Seizures. Pediatric Clin North Am. 1994;41(5):1069-1104. Available from: https://dx.doi.org/10.1016/s0031-3955(16)38846-0.

23. Shakya KN, Shrestha R, Baral MR. Epilepsy in children: an epidemiological study at Kathmandu Medical College Teaching Hospital Kathmandu. Kathmandu Univ Med J (KUMJ). 2003;1(1):14-19.

24. Ojha AR, Ojha UR. Clinico-etiological profile of children with seizures admitted in a tertiary centre. J Kathmandu Med Coll. 2015;4(2):55-58. Available from: https://doi.org/ 10.3126/jkmc.v4i2.15034.

25. Sil A, Das K, Das NK, Chakraborty D, Mazumdar G, Tripathi SK. Use of anti-epileptic drugs in a tertiary care hospital of Eastern India with emphasis on epilepsy due to neurocysticercosis. Indian J Pharmacol. 2012;44(1):106-110.

Copyright: (C) the author(s), 2020. It is an open-access article distributed under the terms of the Creative Commons Attribution License (CC BY 4.0), which permits authors to retain ownership of the copyright for their content, and allow anyone to download, reuse, reprint, modify, distribute and/or copy the content as long as the original authors and source are cited.

How to cite this article: Suryavanshi AR, Bodhgire SB, Phulari SS, Anerao RD. Profile of Children Presenting with Epilepsy at a Tertiary Care Centre: A Hospital Based Cross Sectional Study. Asian J. Clin. Pediatr. Neonatol. 2020;8(3):12-16.

DOI: dx.doi.org/10.47009/ajcpn.2020.8.3.3

Source of Support: Nil, Conflict of Interest: None declared. 